Doctrina

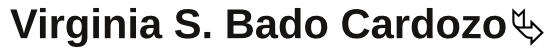

\section{Insolvencia inminente y situación económica difícil. Recepción de la pre-insolvencia en el Derecho uruguayo}

\author{
Imminent Insolvency and Difficult Economic Situation. \\ Reception of Pre-Insolvency in Uruguayan Law \\ Insolvência iminente e situação económica difícil. \\ Recepção da pré-insolvência na lei uruguaia
}

Resumen: La insolvencia inminente y la situación económica difícil integran el estadio conocido como pre-insolvencia, preámbulo de la insolvencia propiamente dicha, caracterizado por la existencia de dificultades económicas, que en principio no serían tan graves como para justificar la apertura de un proceso concursal - con todos los efectos adversos que supone al deudor y al crédito-, pero que se aconseja atender de forma inmediata para evitar la completa destrucción de los activos del deudor.

El trabajo analiza la recepción de estos conceptos en el ordenamiento jurídico uruguayo, fundamentalmente en comparación con el tratamiento que de ellos se hace en España y Portugal.

Palabras clave: crisis, grave dificultad económica, fondos de garantía, insolvencia, insolvencia inminente.

Abstract: The imminent insolvency and the difficult economic situation comprise the stage known as pre-insolvency, preamble of insolvency proper, characterized by the existence of economic difficulties, which in principle would not be so serious as to justify the opening of a process bankruptcy — with all the adverse effects that it implies to the debtor and to the credit-, but that is advised to take care of immediately to avoid the complete destruction of the assets of the debtor.

\footnotetext{
$\stackrel{\leftrightarrow}{\longrightarrow}$ Profesora agregada de Derecho Comercial de la Universidad de la República (Uruguay). Doctora (Universidad de Valencia, España). Doctora en Derecho y Ciencias Sociales (Universidad de la República, Uruguay). ORCID: 0000-0002-3024-8766.

$\triangle$ vbado@derechocomercial.edu.uy
} 
The paper analyzes the reception of these concepts in the Uruguayan legal system, fundamentally in comparison with the treatment of them in Spain and Portugal.

Keywords: Crisis, Serious Economic Difficulty, Guarantee Funds, Insolvency, Imminent Insolvency.

Resumo: A insolvência iminente e a situação económica difícil compreendem a fase conhecida como pré-insolvência, preâmbulo da própria insolvência, caracterizada pela existência de dificuldades económicas, que em princípio não seriam tão graves que justificassem a abertura de um processo. falência —com todos os efeitos adversos que isso implica para o devedor e para o crédito-, mas que é aconselhável tomar cuidado imediatamente para evitar a destruição completa dos bens do devedor.

$O$ artigo analisa a recepção desses conceitos no sistema jurídico uruguaio, fundamentalmente em comparação com o tratamento dos mesmos na Espanha e em Portugal.

Palavras-chave: crise, grave dificuldade econômica, fundos de garantia, insolvência, insolvência iminente.

Recibido: 20190807

Aceptado: 20190907

\section{Sumario}

I. El endeudamiento y la respuesta concursal en Uruguay, España y Portugal. A. Uruguay. B. Portugal. C. España.

II. La insolvencia inminente A. Concepto. B. Recepción en el Derecho uruguayo. C. Recepción en el Derecho portugués y español. 1. La fuente alemana 2. El Derecho portugués 3. El Derecho español

III. El concepto jurídico de grave dificultad económica

A. Concepto. B. Recepción en Uruguay. 1. Las dificultades económicas en el sector financiero. 2. La grave dificultad económica en el sector sanitario. C. Recepción en el Derecho portugués 1. Concepto 2. La situación económica difícil como presupuesto objetivo de procesos y regímenes de alivio al deudor en Portugal. 


\section{Introducción}

Alemania, España y Portugal contemplan, expresamente, la denominada insolvencia inminente como presupuesto objetivo de apertura del proceso concursal, independiente y diferente del presupuesto objetivo insolvencia actual.

En Portugal existe, además, la situação económica difícil como presupuesto objetivo de acceso al Processo Especial de Revitalização (PER), al Processo Especial para Acordo de Pagamento (PEAP) y al Regime Extrajudicial de Recuperação de Empresas (RERE).

La insolvencia inminente y la situación económica difícil integran el estadio conocido como pre-insolvencia, preámbulo de la insolvencia propiamente dicha, caracterizado por la existencia de dificultades económicas, frecuentemente financieras, que en principio no serían tan graves como para justificar la apertura de un proceso concursal — con todos los efectos adversos que supone al deudor y al crédito - pero que se aconseja atender de forma inmediata para evitar la completa destrucción de los activos del deudor (Fernández del Pozo, 2001, p. 7) (Serra, 2018, p. 309).

La Ley 18.387/2008, de 23 de octubre, de Declaración Judicial del Concurso y Reorganización Empresarial (LCU) no refiere a la insolvencia inminente. Tampoco refiere a la situación económica difícil. El propósito de este trabajo es demostrar que estos conceptos no son ajenos al Derecho uruguayo y que pueden definirse con la finalidad de ser utilizados como presupuesto para acceder a procedimientos y regímenes que permitan al deudor evitar el estado de insolvencia.

Desde el punto de vista metodológico hemos analizado y sistematizado la doctrina que estudia las ventajas y desventajas de los regímenes jurídicos que recogen estos conceptos: el Derecho portugués y el Derecho español pues Uruguay no debería ignorar las razones del sobreendeudamiento en Portugal y en España, ni muchos menos las soluciones jurídicas que allí se han implementado para aliviar sus consecuencias. 


\section{El endeudamiento y la respuesta concursal en Uruguay, España y Portugal}

\section{A. Uruguay}

En los últimos años Uruguay experimentó un período de bonanza económica que se reflejó en un reducido nivel de endeudamiento. Sin embargo, ya no es así. Según el Banco Central del Uruguay, los uruguayos presentan síntomas de endeudamiento en exceso ${ }^{(1)}$ y cada vez es más frecuente el cierre de establecimientos comerciales o industriales.

Las crisis no son ajenas a los uruguayos quienes superaron dos períodos muy complicados en los años 1982 y 2002. En aquellos años estos problemas se solventaron fundamentalmente con diversos instrumentos entre los cuales cabe destacar las leyes de refinanciación de la deuda interna y los fondos de garantía. Las leyes de refinanciación permitieron a los deudores aliviar sus deudas con el sistema financiero mediante la obtención de esperas y rebajas en los intereses y los fondos de garantía se utilizaron para garantizar el cumplimiento de las obligaciones asumidas por determinadas entidades de intermediación financiera. Se trató, siempre, de soluciones parciales de apoyo a la legislación concursal vigente.

Superada la crisis el país no adoptó ninguna solución que resolviera el endeudamiento excesivo, ni que lo previniera, hasta que en 2008 se derogaron las normas sobre la quiebra establecidas en el Código de Comercio y se sancionó la Ley 18.387/2008, de Declaración Judicial de Concursos y Reorganización Empresarial, de 23 de octubre $(\mathrm{LCU})^{(2)}$. Esta Ley se aplica a la persona física que realice actividad empresarial y a la persona jurídica civil o comercial. Se considera actividad empresaria a la actividad profesional, económica y organizada con la finalidad de producción o de intercambios de bienes o servicios. Se encuentran excluidos del ámbito de aplicación de esta Ley el Estado, los Entes Autónomos, los Servicios Descentralizados, los Gobiernos Departamentales y las entidades de intermediación financiera, con excepción de las normas relativas a la calificación del concurso, contenidas en el Título IX.

Las personas físicas que no desarrollen actividad empresaria tienen su propio régimen concursal establecido en los artículos 452 a 471 del Código General del Proceso (CGP). Asimismo, las entidades de intermediación financiera tienen un régimen especial dispuesto en el Decreto Ley 15.322/1982, de 17 de setiembre, de 
Intermediación Financiera (LIF), con las modificaciones introducidas por la Ley 16.327/1992, de 11 de noviembre. Lo dispuesto por esta Ley debe ser complementado por las normas incluidas en las leyes dictadas como consecuencia de la crisis que afectó al sistema bancario en el año 2002 y que determinó la intervención y suspensión de actividades de varios bancos en Uruguay, caso de la Ley $17.523 / 2002$, de 4 de agosto, la Ley 17.542/2002, de 21 de agosto y la Ley $17.613 / 2002$, de 27 de diciembre.

El sistema concursal uruguayo se presenta, por tanto, complejo, pues existen varios regímenes concursales. Dejando de lado a las entidades de intermediación financiera de las cuales no habremos de ocuparnos, correspondería preguntarse si es atractivo para solucionar las dificultades económicas de las personas físicas y jurídicas.

En el año 2018 se presentaron ochenta y dos solicitudes de insolvencia (sesenta y nueve en la capital y trece en el interior de la República). De ellas, cinco correspondieron a personas físicas sin actividad empresarial (dos en Montevideo y tres en el interior). En el año 2017 hubo cien solicitudes de concurso en el país (ochenta y seis en Montevideo y catorce en el interior). Sólo cinco de estas solicitudes se presentaron por personas físicas sin actividad empresarial y cuatro se iniciaron en el interior del país. En el 2015 se solicitaron ochenta y cinco solicitudes de insolvencia (setenta y dos en Montevideo y trece en el interior). Sólo hubo dos solicitudes de personas físicas sin actividad empresarial y las dos se presentaron en Montevideo.

Los números sugieren que el concurso no es un proceso estimulante. Pese a las dificultades económicas las personas no recurren al proceso de insolvencia. No lo hacen los empresarios, pero fundamentalmente, no lo hacen las personas físicas sin actividad empresarial.

\section{B. Portugal}

Con la adhesión de Portugal a la Comunidad Económica Europea, en 1986, se produjo la liberalización y el desarrollo del sistema financiero, la disminución de las tasas de interés y de la inflación con el consecuente acceso al crédito.

En veinte años Portugal pasó de una situación de represión financiera a una realidad en la que se privilegiaron los mecanismos de mercado. Las familias portuguesas, a partir de ese momento, cambiaron el hábito de ahorrar por el de consumir y se sobreendeudaron fundamentalmente para la adquisición de la primera vivienda. 
Lo hicieron de buena fe, convencidas de que el nuevo entorno les permitiría cumplir con los pagos ${ }^{(3)}$.

En 2008 comenzó la crisis inmobiliaria y se produjo un crecimiento de más del $10 \%$ en las solicitudes de insolvencias de las personas físicas en sólo un año.

En el primer trimestre de 2012 se declararon 3900 insolvencias. De ellas, 2230 correspondieron a personas físicas. Eso supone que en Portugal se verificó un aumento del 76,8 \% en comparación con el período anterior. Los datos estadísticos elaborados a septiembre de 2012 demostraron que el número de insolvencias de personas jurídicas aumentó un 50 \%, mientras que el de las personas físicas lo hizo en un $70 \%{ }^{(4)}$.

En 2014, de las 14.625 declaraciones de insolvencias decretadas, 10.242 correspondieron a personas físicas sin actividad empresarial. La situación se mantuvo en 2015. En ese año se declararon 15.292 insolvencias de las cuales 10.585 fueron de personas físicas no empresarias

En el tercer trimestre del 2016 se constató un aumento de 3,5 puntos porcentuales con respecto al mismo período de 2015. Durante los años 2017 y 2108 la situación permaneció estable confirmándose el aumento de las declaraciones de insolvencia de las personas físicas en detrimento del de las empresas ${ }^{(5)}$.

Portugal lleva números detallados de las personas que se acercan al Gabinete de Apoio Ao Sobre-Endividado. En 2016 aumentó el número de familias que solicitaron ayuda a la Asociación de Defensa del Consumidor en Portugal. Fueron 29.530 personas; 474 más que en 2015. Se trata de individuos que rondan los 35 a 45 años, educados (en su mayoría han completado el secundario e incluso tienen estudios superiores) y que gozan de rentas mínimas mensuales de aproximadamente $1000 €$. En 2018 se contactaron 29.350 personas. Casi la mitad declaró tener entre 40 y 54 años, haber culminado sus estudios secundarios y percibir una renta líquida mensual de $1.200 €$. En este período la Asociación de Defensa del Consumidor concluyó que el desempleo ha sido la principal causa de las dificultades financieras. Sin embargo, a pesar de estar fuertemente sobreendeudados y sin empleo, las familias tienen una tasa modesta de incumplimiento pues sacrifican ciertos hábitos de consumo, incluso las prestaciones de salud, de modo de mantener el nivel de vida de los hijos y cumplir con la deuda hipotecaria( ${ }^{(6)}$. 


\section{España}

En España el sobreendeudamiento es un problema originado a mediados y fines de la década de los 90 en alguna medida por la estabilidad en el empleo y un crecimiento considerable en la creación de puestos de trabajo. En tales condiciones el mercado se vio invadido de un crédito accesible que propició el aumento del crédito hipotecario.

El incremento de la renta, la liquidez circulante y la situación de estabilidad generó a los españoles la sensación de que podían cumplir sus obligaciones hipotecarias a largo plazo y se endeudaron en unas condiciones favorables que infelizmente no se pudieron mantener (Gutiérrez de Cabiedes, 2009, p. 21).

Sin embargo, la situación no podía sostenerse, siquiera teóricamente, pues los contratos de préstamo con garantía hipotecaria se pactan a un plazo tan extenso (por lo general treinta años), que mantiene al deudor prácticamente durante toda su vida activa pendiente del pago. Cualquier merma de sus ingresos pone en riesgo su capacidad de cumplimiento. Se produce un sobreendeudamiento sobrevenido, esto es, posterior al momento de celebración del contrato, muy difícil de controlar.

En comparación, el endeudamiento excesivo como consecuencia de la conducta desordenada en los hábitos de consumo fue padecido con especial crudeza por la población inmigrante residente en España, lo cual puede explicarse en la incapacidad de controlar los estímulos que ofrece un mercado más atractivo al de sus países de origen ${ }^{(7)}$.

El endeudamiento no ha parado desde entonces. Mientras que el gasto medio por hogar en 2016 fue de 28.199,88 €, la renta media por hogar fue de $26.730 €$, lo que significa que en el período considerado los hogares españoles gastaron más de lo que ganaron ${ }^{(8)}$.

En este escenario sorprende la respuesta de la legislación concursal, fundamentalmente respecto de la persona física. La cifra más alta de concursos declarados para personas físicas sin actividad empresaria se situó en el año 2009 con 1022 concursos. En 2014, año de introducción en España de la primera versión del mecanismo de exoneración del pasivo restante, que no alcanzaba a la persona natural, los concursos de personas físicas no empresarias descendieron un 9,8 \%. En 2015 se declararon 594 concursos de personas físicas no empresarias lo cual representa 
un descenso en un $8 \%$ respecto al año anterior. La cifra no deja de sorprender pues en ese período entró en vigor la Ley 25/2015, de 28 de junio, de mecanismo de Segunda Oportunidad, reducción de la carga financiera y otras medidas de orden social que amplió el mecanismo de la segunda oportunidad a las personas naturales. El 2016 cerró con 674 concursos $^{(9)}$. En 2017 se observa un incremento significativo (56 \%) pues se declararon 1036 concursos. En 2018 puede decirse que la situación permanece incambiada pues se declararon 1054 concursos lo que representa un aumento de $0,8 \%$. Pareciera que el mecanismo de la segunda oportunidad resulta ahora estimulante a estos deudores, sobre todo a los catalanes que representan el 40 $\%$ de estos procesos (en Cataluña se ha verificado un aumento del 73,65 \% respecto al año anterior) $)^{(10)}$.

\section{La insolvencia inminente}

\section{A. Concepto}

La insolvencia inminente es la amenaza de insolvencia, aunque, según se verá, no cualquier amenaza de insolvencia interesa al Derecho. Sólo es relevante aquélla que, en tanto presupuesto objetivo, permite la apertura de algún proceso tendente a considerar la situación de crisis, sea anticipando la declaración de insolvencia, sea permitiendo el acceso a procesos o soluciones que eviten la declaración de insolvencia.

La mayor o menor utilidad del presupuesto depende del régimen jurídico, pero, lo importante, es que la amenaza de insolvencia, igual que la insolvencia misma, sólo es presupuesto objetivo cuando alcanza el grado de estado, esto es, cuando se prolonga en el tiempo. No hay insolvencia inminente si se trata de dificultades transitorias.

La insolvencia inminente es, pues, un concepto técnico que se construye con la combinación de dos elementos complejos. De un lado, un necesario pronóstico o prognosis respecto de la probabilidad de la imposibilidad para cumplir con las obligaciones más inmediatas. El objeto del pronóstico del deudor debe concluir en un estado de imposibilidad de cumplimiento, así como la insolvencia relevante es la que alcanza el grado de estado de imposibilidad del deudor para cumplir con sus obligaciones (Rojo Fernández-Río, 2008, pp. 164-193).

La mera posibilidad de insolvencia no es suficiente para conformar la insolvencia inminente pues el riesgo de insolvencia es inherente a la actividad empresarial. La amenaza no debe ser posible, ni potencial; la amenaza debe ser real, lo que ne- 
cesariamente obliga a considerar el término inminente.

El Diccionario establece que inminente significa que amenaza o está para suceder prontamente(11), de ahí que la imposibilidad debe ser de ocurrencia probable a corto plazo, esto es, amenazante. Por esta razón, la inminencia no surge por el número o la importancia de las obligaciones incumplidas, sino por el resultado de la comparación entre la liquidez del activo y la exigibilidad del pasivo considerando el factor tiempo. La insolvencia inminente sólo lo es si la insolvencia es objetivamente probable que se produzca a corto plazo. Cuán corto ha de ser este plazo es una de las cuestiones más difíciles de resolver, sobre todo cuando el legislador no ha querido establecer los límites temporales de la inminencia (caso del español y el portugués por citar regímenes jurídicos que han regulado este presupuesto expresamente). Es evidente que no hay amenaza de insolvencia si el estado de insolvencia se pronostica para dentro de un año y es igualmente evidente que lo habrá si es posible preverlo para dentro de un mes. El problema es resolver aquello que no es evidente; las zonas intermedias. Para estos casos la mejor solución parece ser establecer una regla general que se aplique a cualquier deudor, sin importar el sector al que pertenezca (Rojo Fernández-Río, 2008, pp. 176 y 177).

\section{B. Recepción en el Derecho uruguayo}

La LCU no refiere expresamente a la insolvencia inminente. En rigor, no establece tipos de insolvencia, ni inminente, ni actual, ni calificada como la Ley 22/2003, de 9 de julio, Concursal (LCE) ${ }^{(12)}$.

La LCU refiere, sólo, a la insolvencia, a la que define como el estado en que se encuentra el deudor que no puede cumplir con sus obligaciones (art. 1). Se requiere, por tanto, una situación que impida cumplir, pero no un efectivo incumplimiento. No es necesario, pues, llegar al efectivo incumplimiento para justificar la solicitud de declaración de concurso bastando que el deudor se encuentre en un estado de impotencia de pagar las deudas.

La Ley no distingue y por ello debe interpretarse que se refiere a las obligaciones vencidas y a las que habrán de vencer próximamente, lo que en el Derecho español se conoce como la insolvencia actual y la insolvencia inminente, respectivamente $^{(13)}$ (Bado Cardozo y López Rodríguez, 2012, p.65). 
La interpretación sugerida fue sustentada en el régimen de la quiebra (Rodríguez Olivera, 2005, pp. 87 y 88)y hoy se recoge en el artículo 5, numeral 1 de la LCU, como una presunción legal absoluta de insolvencia ${ }^{(14)}$.

Las presunciones legales absolutas obligan a tener por cierto un hecho en tanto otro hecho, que ha de comprobarse fehacientemente, lo indique (Tarigo, 2004, p. 149). En el caso que nos ocupa, lo que hay que tener por cierto es el estado de insolvencia y el hecho indiciario fehaciente es la solicitud del deudor. Se trata, éste, de un hecho tan elocuente que no admite prueba en contrario. En efecto, el artículo 10 de la LCU establece que el deudor tiene la obligación de solicitar su propio concurso dentro de los treinta días siguientes a que hubiera conocido o debido conocer su estado de insolvencia.

La denominada obligación de solicitar el concurso es, en realidad, una carga ${ }^{(15)}$ que se justifica en el interés público en evitar que el deudor agrave sus dificultades y se anticipe a los acreedores, advirtiéndoles su situación (Bado Cardozo y López Rodríguez, 2012, pp. 142 y 143).

No debe llamarnos la atención que nuestra Ley no recogiera el concepto de insolvencia inminente expresamente. La insolvencia inminente no se encuentra en la Propuesta de Anteproyecto de Reforma de la Legislación Concursal (PALC) que sirvió de fuente de nuestra legislación. Se incorporó, sí, a la LCE en cuya Exposición de Motivos se alude a la intención de anticipar en el tiempo la declaración de concurso, para lo cual se permite que la declaración de concurso tenga lugar cuando la insolvencia no se ha producido, sino que sea de producción inminente (Beltrán Sánchez, 2007, pp. 1737-1753).

A pesar de todo, la insolvencia inminente no es ajena ni a la PALC, ni a la LCU pues en la Exposición de Motivos de ambos textos aparece explícito el interés del legislador en permitir la apertura temprana del concurso estimulando al deudor a solicitar su propio concurso. La forma de hacerlo es exonerándole de la carga probatoria de una insolvencia que, sin ser actual, es amenazante y que el propio deudor pronostica y confiesa ${ }^{(16)}$. Todo ello con la idea de que los procedimientos concursales se utilicen antes de que el deterioro de la actividad del deudor sea irreversible ${ }^{(17)}$. De ahí que puede entenderse que el presupuesto objetivo pensado por el legislador uruguayo (estado de insolvencia) sea lo suficientemente flexible como para comprender, no sólo a la insolvencia, sino, también, a la amenaza de insolvencia o insolvencia inminente $\mathrm{e}^{(18)}$. 


\section{Recepción en el Derecho portugués y español}

\section{La fuente alemana}

Portugal y España han incorporado a su legislación concursal la insolvencia inminente cuyo origen se halla en el párr. 18 de la Orden de Insolvencia del 5 de octubre de 1994, Insolvenzordnung (InsO), norma que contempla la Drohende Zahlungsunfähigkeit, o amenaza de insolvencia, como un motivo que permite al deudor solicitar la declaración de insolvencia, motivo que se añade al tradicional presupuesto insolvencia actual o real, Zahlungsunfähigkeit, referida en párr. 17 (1) de la InsO.

La insolvencia inminente en Alemania se configura cuando es improbable que el deudor pueda cumplir con sus obligaciones de pago existentes al vencimiento. Es diferente, pues, de la insolvencia propiamente dicha, que se configura con la incapacidad para efectuar los pagos correspondientes a las obligaciones vencidas.

\section{El Derecho portugués}

En el Derecho portugués el presupuesto objetivo de apertura del proceso de insolvencia es la situação de insolvência, condición que se define en el artículo 3.1 del Decreto Ley 53/2004, de 18 de marzo, Código da Insolvência e da Recuperação de Empresas (CIRE), como a impossibilidade de cumprimento das obrigações vencidas, situación que, lejos de suponer una mera insuficiencia patrimonial (Leitão, 2018, p. 83), es un estado determinado por la imposibilidad de cumplir puntalmente con las respectivas obligaciones (Martins, 2016, p. 42.). A su lado se ubica la insolvencia inminente.

A diferencia del legislador español, el legislador portugués no define la insolvencia inminente ni establece cuándo se incurre en ella. El artículo 3.4 del CIRE se limita a declarar que la insolvencia inminente habrá de equiparase a la insolvencia actual en lo que respecta a la solicitud de declaración de insolvencia realizada por el propio deudor. Los acreedores no pueden hacerlo para evitar presiones al deudor (Abreu, 2018, p. 140) y además porque seguramente el legislador ha considerado que sólo el deudor puede realizar el juicio de previsibilidad sobre la posibilidad o imposibilidad de cumplimiento que supone la inminencia de la insolvencia (Rojo Fernández-Río, 2008, p. 175). 
La doctrina portuguesa discute si el deudor tiene el deber de solicitar su declaración de insolvencia en caso de amenaza, o si ello es una facultad. Existe quien entiende que se trata de una facultad; que el deudor puede, si lo desea, adelantarse y solicitar su declaración de insolvencia cuando verifica que no podrá cumplir con los próximos vencimientos (Leitão, 2017), pues el deber de solicitar la declaración de insolvencia aparece con la insolvencia efectiva (Leitão, 2017, p. 84 ), De otro lado, existe quienes entienden que el deudor tiene el deber de solicitar su declaración de insolvencia cuando se verifica esta insolvencia inminente (Carvalho Fernandes y Labareda, 2015, pp. 84-85).

La insolvencia inminente es el resultado de un juicio de probabilidad que realiza el deudor quien prevé, con verosimilitud, que probablemente - lo que se interpreta como casi una certeza - no tendrá medios para cumplir con la generalidad de sus obligaciones existentes al momento de su vencimiento (Abreu, 2018, p. 139)(Serra, 2012, pp. 176 y 177)(Fernandes y Labareda, 2015, pp. 71-72.).

Debe afinarse este aspecto de modo de resolver si las obligaciones han de estar definitivamente incumplidas o no. Algunos autores incluyen el riesgo de incumplimiento de las obligaciones vencidas (Fernandes y Labareda, 2015, pp. 71-72), otros restringen el concepto a la inminencia de incumplimiento y aclaran que no se exige la imposibilidad de cumplimiento de deudas vencidas, bastando su proximidad (Ruy de Alburquerque, 2007, pp. 773-793). Se va, todavía, más lejos y se incluyen otras que no son actuales pero que probablemente serán contraídas y vencerán durante un período de tiempo a considerar (Martins, 2016, pp. 511 y ss.). En términos genéricos se alude, finalmente, a un futuro próximo como forma de extender la inminencia (Serra, 2012, pp. 176 y 177). Como puede apreciarse, Portugal tampoco ha resuelto el problema de los límites de la inminencia, lo que parece ser el verdadero problema.

Con esta insolvencia meramente inminente el deudor puede, además de solicitar la declaración de su insolvencia, acceder al Processo Especial para Acordo de $\mathrm{Pa}$ gamento (PEAP) previsto en los artículos 222 A -I, del CIRE. Se trata de un procedimiento que se pretende rápido y eficaz para atender el sobreendeudamiento de las personas físicas y jurídicas no empresarias. Es un mecanismo de tratamiento preinsolvencial de modo que el deudor no debe haber caído en estado de insolvencia. 


\section{El Derecho español}

La Ley 22/2003, de 9 de julio, Concursal (LCE), establece que la declaración de concurso procederá respecto de cualquier deudor, sea persona natural o jurídica, que se encuentre en estado de insolvencia. La insolvencia en España es, pues, un estado en que se encuentra el deudor que no puede cumplir regularmente con sus obligaciones exigibles (arts. 1 párr. 1 y 2 párr. 2).

El estado de insolvencia se revela en el hecho externo incumplimiento, hecho en el que el deudor debe apoyar su solicitud de declaración de concurso. No es el único. Existen otros hechos externos a los que la LCE considera especiales por afectar a ciertos acreedores. Se encuentran dispuestos en el art. 2.4 de la LCE y determinan lo que la doctrina denomina insolvencia actual cualificada. Se trata del incumplimiento generalizado de obligaciones de pago de tributos exigibles durante los tres meses anteriores a la solicitud de concurso, de pago de cuotas de la Seguridad Social y demás conceptos de recaudación conjunta durante el mismo período y en el incumplimiento en el pago de salarios e indemnizaciones y demás retribuciones derivadas de las relaciones de trabajo correspondientes a las tres últimas mensualidades (Rojo Fernández-Río, 2008, p.175 ).

Con independencia de la insolvencia actual o real, a la que hemos hecho referencia en los párrafos precedentes, el legislador español define y regula expresamente la insolvencia inminente. El deudor se encuentra en estado de insolvencia inminente cuando prevé que no podrá cumplir regular y puntualmente con sus obligaciones (art. 2 párr. 3). Esta insolvencia, a diferencia de la real y la cualificada, no debe demostrarse o revelarse en ningún hecho externo, en ningún incumplimiento, porque el deudor todavía no ha incumplido (Rojo Fernández-Río, 2008). La prueba de la insolvencia inminente versa sobre la objetividad del juicio de probabilidad, esto es, sobre el carácter objetivo del pronóstico que hace el deudor de la probabilidad de su insolvencia real (Rojo Fernández-Río, 2008, p. 175) (Prendes Carril, 2009, pp. 92 y 93) (Suárez-Llanos Gómez, 2005, pp. 35-48).

Tal como sucede en Portugal, el legislador español no ha definido los límites temporales de la inminencia, esto es, cuán amenazante debe ser la insolvencia para conformar el presupuesto objetivo y permitir la apertura del proceso concursal. Existe acuerdo respecto a que la insolvencia inminente lo es si la insolvencia es objetivamente probable que se produzca a corto plazo, pero no existe acuerdo respecto a cuán corto ha de ser éste plazo. Rojo Fernández-Río razona que no hay amenaza de insol- 
vencia si el estado de insolvencia se pronostica para dentro de un año y que lo habrá si es posible preverlo para dentro de un mes. No existiendo parámetros ciertos para resolver las zonas intermedias, el autor considera apropiado establecer como límite de inminencia el plazo de seis meses, pues uno de los hechos externos que revelan el estado de insolvencia actual en la LCE es el incumplimiento durante los tres meses anteriores a la solicitud de concurso (art. 2.4-4) (Rojo FernándezRío, 2008, pp. 176 y 177)

Al igual que en el Derecho portugués, la insolvencia inminente en España es un presupuesto objetivo restringido al deudor; los acreedores no pueden solicitar la declaración del concurso de su deudor apoyándose en su insolvencia inminente pues el legislador ha considerado que sólo el deudor puede realizar el juicio de previsibilidad sobre la posibilidad o imposibilidad de cumplimiento que supone la inminencia de la insolvencia. Se entiende que esta restricción supone una limitación a la operatividad del presupuesto objetivo que satisface parcialmente la conveniencia de adelantar en el tiempo la declaración judicial de concurso (Rojo Fernández-Río, 2008, p. 175).

En España, que el deudor se encuentre en situación de insolvencia inminente no determina un rito diferente del que corresponde al deudor que se encuentra en estado de insolvencia actual. Todos recorren el mismo procedimiento concursal en virtud del principio de unidad de sistema. El legislador español ha considerado que la Ley es lo suficientemente flexible para atender las situaciones de insolvencia inminente y actual, aunque supongan estados patrimoniales diversos (Rojo FernándezRío, 2008, p. 178).

\section{El concepto jurídico de grave dificultad económica}

\section{A. Concepto}

Los regímenes jurídicos que contemplan la grave dificultad económica ponen el acento en los problemas que enfrenta el deudor para cumplir con sus obligaciones, situación que debe revestir cierta gravedad al punto de impedir al deudor cumplir con sus obligaciones. Se descartan, por tanto, los incumplimientos circunstanciales. La situación de grave dificultad económica necesita un grado de relevancia; una perdurabilidad que descarta un escenario desfavorable meramente transitorio. Asimismo, no cualquier situación de grave dificultad económica es relevante para el Derecho; sólo lo es en tanto constituya el presupuesto objetivo que permita al deu- 
dor el acceso a procedimientos o fórmulas jurídicas que solucionen o alivien sus dificultades económicas.

\section{B. Recepción en Uruguay}

Las dificultades económicas no son ajenas al Uruguay. La más reciente ocurrió en el 2002, oportunidad en la que el país sufrió una crisis financiera y económica muy importante. En aquél momento se implementaron una serie de medidas legislativas con el fin de paliar sus consecuencias y una de ellas fue la creación de unos fondos de garantía. También se utilizaron para atender la crisis en el sector asistencial derivado de ciertos problemas con algunas instituciones que integran el denominado Sistema Integrado de Salud.

Los fondos de garantía no son una novedad en el Derecho uruguayo. Se han creado con diferentes objetivos, a veces con un propósito social (para estimular a la micro y pequeña empresa o para favorecer el acceso a la vivienda), otras veces, como adelantáramos, para atender a las personas en momentos de crisis (los mejores ejemplos se encuentran en el sector financiero y recientemente en el sector sanitario).

Son ejemplos de fondos de naturaleza promocional el Fondo Nacional de Garantía establecido en la ley 16.622/1994, cuyo objeto es garantizar los créditos que se otorguen a estas empresas, existentes o que pretendan establecerse, que demuestren a la Corporación Nacional para el Desarrollo — administrador del Fondo-, la viabilidad técnica de la actividad, entre otros requisitos establecidos en el artículo 4. El presupuesto objetivo de acceso a este fondo es, pues, un criterio relacionado con el éxito o con el fracaso de la actividad empresarial. También con este mismo espíritu se creó un Fondo de Garantía de Alquileres por Decreto 100/2002, de 12 de marzo, en el ámbito de la Dirección Nacional de Vivienda, con el objeto de otorgar la garantía necesaria para que las personas de bajos recursos pudieran acceder a una vivienda. Posteriormente este Fondo se derogó por el Decreto 561/2006, de 11 de diciembre, y se sustituyó por la política de promoción y acceso a la vivienda de la ley 18.125/,2007, de Modificación a la Carta Orgánica del Banco Hipotecario del Uruguay que creó la Agencia Nacional de Vivienda encargada de constituir y gestionar los fondos de inversión y fideicomiso con ese mismo objeto.

Asimismo, se crea el Fondo de Garantía de Créditos Hipotecarios por Ley 18.795/2011, de 17 de agosto, de Promoción de la Vivienda de Interés Social, que beneficia a las personas físicas deudoras de un crédito hipotecario en tanto posean 
una adecuada capacidad de devolución del préstamo hipotecario otorgado (art. 16 del decreto 95/2012, de 27 de marzo, Reglamentario).

\section{Las dificultades económicas en el sector financiero}

\section{a. Del incumplimiento de los depósitos a la resolución de suspen- sión y liquidación del intermediario financiero}

La última gran crisis que sufrió Uruguay fue en el 2002 y se comenzó a salir de ella, entre otras medidas, gracias a la creación del Fondo de Estabilidad de la ley 17.523, de 4 de agosto de 2002, de Fortalecimiento del Sistema Bancario, integrado con recursos de organismos multilaterales de crédito a los efectos de garantizar el cumplimiento de los depósitos de los ahorristas del sector no financiero en moneda extranjera existentes al 30 de julio de 2002 en el Banco de la República y el Banco Hipotecario, en cuenta corriente o en caja de ahorro. El legislador, en esta oportunidad, no estableció un presupuesto objetivo claramente determinado.

Posteriormente se sanciona la ley 17.613/2002, de 27 de diciembre, también denominada de Fortalecimiento del Sistema Bancario. Allí el legislador continuó dando solución al problema de la crisis financiera, pero de una forma más extensiva y estableció, sí, el presupuesto objetivo de acceso al Fondo de Garantía. Determinó que la garantía del Fondo se hacía efectiva cuando se resuelve la liquidación o la suspensión de las actividades del intermediario financiero (art. 49).

La suspensión y a liquidación refieren a situaciones diferentes. La suspensión de las actividades de las instituciones de intermediación financiera se introdujo en la ley 16.327/1992, de 3 de noviembre, como una medida preventiva a la liquidación. Es una potestad que el legislador confiere al Banco Central del Uruguay en el artículo 35 de esta Ley. La suspensión puede ser propuesta por la Superintendencia de Servicios Financieros según el artículo 38 de la Ley 16.696/1995, de 30 de marzo, en la redacción dada por la Ley 18.401/2009, de 24 de octubre (art. 11, lit., M). La liquidación, en cambio, es una medida de naturaleza solutoria que sigue un rito administrativo dirigido por la Corporación de Protección del Ahorro Bancario (CO$\mathrm{PAB}$ ), persona jurídica de Derecho público no estatal creado por la ley 18.401/2009, de 24 de octubre, Modificatoria de la Carta Orgánica del Banco Central del Uruguay (art. 15, lit., C), quien declara la disolución y dirige el procedimiento de acuerdo con lo establecido por la Ley 17.613 y subsidiariamente y en lo pertinente por las normas de liquidación de las sociedades anónimas (art. 14 de la 
Ley 17.613 con los poderes señalados en el artículo 16 de la Ley 18.401).

\section{b. Afectación irreversible e insubsanable de la liquidez, solvencia o capacidad de gestión}

Superada la crisis, la ley 17.613/2002 se derogó parcialmente por la ley 18.401, norma que, como adelantáramos, creó la COPAB. Uno de los cometidos de esta persona es administrar el Fondo de Garantía de Depósitos Bancarios (art. 15, lit., B). La norma amplía el Fondo a todos los depósitos de cualquier naturaleza (excepto los señalados en el artículo 33) constituidos por personas físicas o jurídicas del sector no financiero (excepto los del Gobierno Central y del Banco de Previsión Social y las personas excluidas expresamente en el artículo 32), en las empresas de intermediación financiera a las que se refiere el artículo 17 bis del Decreto Ley 15.322/1982, de 17 de setiembre, de Intermediación Financiera.

En lo que nos interesa, la Ley 18.401 ajusta el presupuesto objetivo de acceso al Fondo de Garantía y sólo lo permite a la institución de intermediación financiera que tenga afectada, en forma irreversible y no subsanable a través de un plan de adecuación, saneamiento o reconstitución, su liquidez, solvencia o su capacidad de gestión (art.40).

La COPAB es la encargada de realizar el proceso de verificación de tales extremos y el Banco Central del Uruguay es quien resuelve una serie de medidas (intervención, desplazamiento de autoridades y suspensión de actividades de la institución) y arbitrar los denominados procedimientos de solución que suponen operaciones de exclusión de activos y pasivos de la institución afectada con cargo al Fondo de Garantía (art. 41).

\section{La grave dificultad económica en el sector sanitario}

\section{a. Concepto}

En el sector sanitario las dificultades económicas se traducen en el concepto grave dificultad económica introducido en la Ley 18.439/2008, de 22 de diciembre, de Creación del Fondo de Garantía para la reestructuración de pasivos de las instituciones de asistencia médica colectiva. Esta situación es definida en su Decreto reglamentario 792/008, de 26 de diciembre de 2008, de Planes de reestructuración como la situación de incapacidad de pago de las obligaciones por los siguientes 
seis meses, siempre y cuando se verifique la existencia de un patrimonio negativo.

La expresión incapacidad descarta el incumplimiento puntual y transitorio de una o de algunas obligaciones, determinando, en cambio, un incumplimiento reiterado que debe, además, pronosticarse para los siguientes seis meses provocando un déficit patrimonial.

\section{b. La situación de grave dificultad económica como presupuesto objetivo de acceso al Fondo de Garantía}

La situación de grave dificultad económica es el presupuesto objetivo de acceso al Fondo de Garantía creado por la Ley 18.439/2008, exclusivamente para las instituciones comprendidas en la Ley 18.211/2007, de 5 de diciembre, de Sistema Integrado de Salud.

En efecto, la Ley 18.439/2008 crea un fondo alimentado con recursos provenientes de las Rentas Generales del Estado (art. 2) afectado a garantizar la devolución del financiamiento obtenido por las instituciones integrantes del Sistema Nacional Integrado de Salud que cumplan dos condiciones acumulativamente: hallarse en una situación de grave dificultad económica y presentar un plan de reestructuración de los pasivos existentes al 30 de septiembre de 2008 que demuestre la viabilidad de la institución ${ }^{(19)}$ (art. 1).

La situación de grave dificultad económica se encuentra definida en el Decreto 792/008, norma que establece los requisitos que deberán cumplir las instituciones para obtener la aprobación de los planes de reestructuración que les permiten acceder al fondo. De modo que en la Ley la situación de grave dificultad económica es un presupuesto objetivo de acceso al fondo y en el Decreto reglamentario lo es para obtener la aprobación del plan de reestructuración que les permite, a su vez, el acceso al fondo.

Como puede apreciarse, el Decreto completa el presupuesto objetivo de tal suerte que el Fondo de Garantía se permite a las instituciones beneficiarias en tanto demuestren al Ministerio de Salud Pública y al Ministerio de Economía y Finanzas la existencia de unas condiciones de viabilidad, esto es, la capacidad de superar la situación de grave dificultad económica, mediante un plan de reestructuración de pasivos y un plan orgánico-funcional, sin afectar la calidad de los servicios de salud, quedando, además, en condiciones de asumir la totalidad de los compromisos 
derivados de su participación en el Sistema Nacional Integrado de Salud (art. 3). Si no logran demostrar esta aptitud quedarán sometidas a las disposiciones de la LC (art. 4).

Para que las instituciones beneficiarias puedan acogerse a la garantía otorgada por el Fondo de Garantía deben realizar un procedimiento administrativo que comienza con una solicitud de acogerse al Fondo de Garantía por un monto determinado ante el Ministerio de Salud Pública acompañada de la documentación que acredite el presupuesto subjetivo y objetivo, esto es, tratarse de una institución comprendida en el Sistema Integrado de Salud que se encuentre en un estado de grave dificultad económica entendiéndose por tal la situación de incapacidad de pago de las obligaciones por los siguientes seis meses, siempre y cuando se verifique la existencia de un patrimonio negativo. De acuerdo con el artículo 7, la solicitud será suficiente para que provisoriamente la institución pueda acogerse al Fondo de Garantía. Cabe preguntarse si este efecto provisorio no desvirtúa la finalidad de la norma de reservar el fondo a las instituciones que acrediten viabilidad.

La solicitud debe acompañarse de los planes de reestructuración que permitan viabilizar la institución y la documentación a que refiere el artículo segundo del Decreto, entre la que vale la pena mencionar los estados contables de los últimos tres ejercicios, auditados por un contador público independiente, el número de afiliados comprendidos en el Seguro Nacional de Salud, los afiliados individuales y en el régimen de libre contratación.

Formando parte del denominado programa de reestructuración la institución debe realizar un detalle informado de los pasivos y allí debe indicar el estado y valuación de los activos, el detalle de los pasivos, el flujo de fondos proyectado sin considerar una reestructuración, los procedimientos de cualquier naturaleza iniciados contra la institución y su estado, los convenios celebrados y finalmente, la modalidad y estructura jurídica propuesta para una reestructuración del pasivo. Esta propuesta debe considerar las garantías reales o personales que ofrece para garantizar sus obligaciones y el flujo de fondos proyectado para la devolución del financiamiento solicitado. El programa de reestructuración de pasivos debe acompañarse de un programa de reestructuración funcional que atiende a preparar a la institución para ajustar la organización a la estructura jurídica propuesta (art. 2).

El plan de reestructuración será evaluado atendiendo a la verificar la viabilidad de la institución. Se considera viable la institución que sea capaz de superar la gra- 
ve situación económica sin afectar la calidad de los servicios de salud, quedando en condiciones de asumir la totalidad de los compromisos derivados del Sistema Nacional de Salud (art. 3).

\section{Recepción en el Derecho portugués}

\section{Concepto}

La situación económica difícil se encuentra definida por el legislador portugués en el Decreto Ley 53/2004, de 18 de marzo, Código da Insolvência e da Recuperação de Empresas (CIRE) como el estado que padece el deudor que enfrenta ...dificuldade séria para cumprir pontualmente as suas obrigações, designadamente por ter falta de liquidez ou por não conseguir obter crédito.

El concepto ya existía en el Derecho portugués. Se utilizó en diversas normas, a veces con un criterio asociado al éxito o al fracaso de la explotación empresarial, en otras con un criterio financiero ${ }^{(20)}$ (Serra, 2018, p. 310).

En el primer significado el Decreto Ley 864/76, de 23 de diciembre, por ejemplo, declaraba a las empresas en situação de crise económica cuando constataba que sobrevivían ...sem contrapartida relevante de produção de riqueza, em bens ou serviços, ou com contrapartida que fica muito aquém daquilo que consome o seu funcionamento, vivem artificialmente à custa do orçamento do Estado, ao abrigo de intervenção ou de recebimento sistemático do que só formalmente se pode chamar «avales» do Estado, já que o respectivo reembolso se mostra ou impossível ou de difícil exequibilidade. En la misma línea, el Decreto Ley 353/-H/1977, de 29 de agosto, definió la situación económica difícil como aquélla situación en la que se encuentra la empresa ...cuja exploração se apresente fortemente deficitária, prevendo-se que a sua recuperação seja problemática ou demorada.

En el segundo significado, asociado a la capacidad financiera o de la liquidez del empresario (Casanova, Salazar y Dinis, 2014, pp. 20 y 21), el artículo 3, n.2, del Código dos Processos Especiais de Recuperação da Empresa e de Faléncia, hoy derogado por el CIRE señalaba en esta situación a la empresa que ... não devendo considerar-se insolvente, indiciava dificuldades económicas e financeiras, designadamente por incumprimento das suas obrigações. 


\section{La situación económica difícil como presupuesto objetivo de procesos y regímenes de alivio al deudor en Portugal}

El CIRE refiere a la situação económica difícil como presupuesto de acceso a dos procesos que se pretenden rápidos y eficaces para atender el sobreendeudamiento: el processo especial de revitalização (PER) y el processo especial para acordo de pagamento (PEAP).

El PER, previsto en el Capítulo II del Título I del CIRE (art. 17, literales A al J), es un proceso que puede recorrer toda empresa que, sin hallare en estado de insolvencia, se encuentre en una situación económica difícil, aunque con posibilidades de recuperación, cuyo objeto es establecer las negociaciones de modo de lograr con los respectivos acreedores un acuerdo tendente a su revitalización ${ }^{(21)}$. El PEAP es prácticamente idéntico. Se aplica a las personas físicas y jurídicas no empresarias que, sin hallarse en estado de insolvencia, se encuentren en una situación económica difícil, cuyo objeto es establecer las negociaciones con los respectivos acreedores de modo de concluir con ellos un acuerdo de pagos. Se encuentra previsto en el Capítulo III del Título IX del CIRE (art. 222, literales A al J).

Luego, la situación económica difícil, es, asimismo, presupuesto para acceder al regime extrajudicial de recuperação de empresas (RERE), establecido en la ley 8/2018, de 2 de marzo de 2018, por el que se regulan los términos y los efectos de las negociaciones y del acuerdo de reestructuración alcanzado entre el deudor y uno o más de sus acreedores, en la medida en que expresa y unánimemente se comprometan a someter sus negociaciones o el acuerdo de reestructuración al régimen de la ley (art.2).

\section{Conclusiones}

La insolvencia inminente y la situación de grave dificultad económica o situación económica difícil son conceptos afines a la insolvencia. Pertenecen al mundo de la pre-insolvencia, ese estadio anterior a la insolvencia, siempre efímero, del cual, o se sale para retomar la actividad en plenitud luego de utilizados los procesos o los regímenes que el Derecho ofrece para atajar la crisis, o se sale para entrar, prontamente, en el procedimiento concursal que permite gestionar esa crisis.

El legislador uruguayo no definió la insolvencia inminente en la legislación concursal; no la distingue de la insolvencia propiamente dicha. No obstante, no 
puede decirse que le sea ajena pues el legislador ha querido que el concurso se inicie apenas se perciban los primeros síntomas de la insolvencia. Incluso puede decirse que ha establecido una regulación específica. Tal es la carga que pesa sobre el deudor que, en los términos del artículo 10, debe solicitar al juez su declaración de insolvencia.

En la legislación concursal actual la insolvencia inminente se traduce en la solicitud de concurso efectuada por un deudor diligente. Pero podría tener una utilidad mucho mayor si se pudiera utilizar como presupuesto para acceder a procedimientos o regímenes que permitan a ese deudor evitar el estado de insolvencia. La experiencia portuguesa relacionada parece alentadora. De lege ferenda, entonces, debería introducirse una definición de insolvencia inminente, no sólo para demostrar el interés explícito del legislador en la pre-concursalidad (lo que aparece un objetivo menor), sino como el primer paso para construir una plataforma de soluciones que eviten el estado de insolvencia. Debería, asimismo, establecerse los límites temporales de la inminencia, pues de ello depende la efectividad de los procedimientos y debería permitirse, además, que cualquier acreedor pudiera solicitar el concurso por insolvencia inminente de modo de efectivamente evitar la completa destrucción de los activos del deudor.

En comparación, la situación de grave dificultad económica o situación económica difícil aparece regulada y ello es, infelizmente, debido a las crisis económicas y financieras que han agobiado al país en los últimos años, tanto en el sector financiero como en el sector asistencial comprometido en el Sistema Integrado de Salud. La respuesta para esta situación no ha sido concursal, sino que ha sido administrativa a través de los fondos de garantía que resultan ser soluciones pre-concursales, de naturaleza extrajudiciales y administrativas. 


\section{Referencias}

Abreu, J. M. Coutinho de (2018). Curso de Direito Comercial, v.1 (11 ed.). Coimbra: Almedina.

Bado Cardozo, V. S. y López Rodríguez, C. E. (2012). Presupuestos del concurso. En López Rodríguez (Dir.), Ley de Declaración Judicial del Concurso y Reorganización Empresarial. Análisis Exegético, t. 1. Montevideo: La Ley.

Beltrán Sánchez, E. (2007). La regularidad en el cumplimiento de las obligaciones, el estado de insolvencia y la función del concurso de acreedores. En AA.VV., Estudios de Derecho de Sociedades y Derecho Concursal: Libro homenaje al Profesor Rafael García Villaverde, t. 3, (pp. 1737-1753). Madrid: Marcial Pons.

Casanova, N., Salazar y Dinis, D. Sequeira (2014). PER. O Processo Especial de Revitalização (Comentários aos artigos $17^{\circ}-A$ a $17^{\circ}-I$ do Código de Insolvência e de Recuperação de Empresas). Coimbra: Coimbra Editora.

Creimer Bajuk, I. (2015). El presupuesto objetivo del concurso. En AA.VV, Crisis y Derecho. Las vías de prevención y saneamiento de la crisis empresarias, (pp. 53-61). Córdoba: Fundación para el Estudio de la Empresa.

Fernandes, L. A. Carvalho y Labareda, J. (2015). Código da Insolvência e da Recuperaçâo de Empresas. Anotado (3 ${ }^{\mathrm{a}}$ ed.). Lisboa: Quid Juris.

Fernández del Pozo, L. (2001). Posibilidad y contenido de un Derecho Preconcursal. Auditoría y prevención de la crisis empresarial (art. 209.1.b) LSA). Madrid: Marcial Pons.

Germán Florio, C. D. (2018). Concepto de insolvencia en el concurso. En Miller, Ferrer y Ayul (Dirs.), Estudios de Derecho Concursal. Diez años de la Ley de Concursos y Reorganización Empresarial, (pp. 387-418). Montevideo: La Ley.

Germán Florio, C. D. (2017). Concurso y estado de insolvencia. Montevideo: La Ley. 
Holz Brandus, E. R. y Rippe Káiser, S. (2009). Reorganización empresarial y concursos. Ley 18.387. Montevideo: FCU.

Leitão, L. M. Teles de Menezes (2018). Direito da Insolvência (8 ${ }^{\mathrm{a}}$ Ed). Coimbra: Almedina.

Leitão, L. M. (2017). Código da Insolvência e da Recuperação de Empresas Anotado ( $9^{a}$ ed.) Coimbra: Almedina.

Martínez Blanco, C. (2018). Manual de Derecho Concursal. De los orígenes de las crisis empresariales a la Ley $N^{\circ} 18.387$ y su aplicación ( $3^{\mathrm{a}}$ ed.). Montevideo: FCU.

Martins, A. de Soveral (2016). Um Curso de Direito da insolvência. Coimbra: Almedina.

Olivera García, R. M. y Chalar Sanz, L. (2018). La Ley uruguaya de concursos y reorganización empresarial. En Olivera (Dir.), Panorama de Derecho Concursal, (pp. 11-25). Montevideo: FCU.

Olivera García, R. M. (2018). La insolvencia empresarial y la eficacia de la herramienta concursal. En Miller, Ferrer y Ayul (Dirs.), Estudios de Derecho Concursal. Diez años de la Ley de Concursos y Reorganización Empresarial, (pp. 31-72). Montevideo: La Ley.

Olivera García, R. M. (2018). La insolvencia como presupuesto del concurso. En Olivera García (Dir.), Panorama de Derecho Concursal, (pp. 39-44). Montevideo: FCU.

Olivera García, R. M. (2011). La insolvencia como presupuesto del concurso. En AA.VV., Tres Pilares del Moderno Derecho Comercial, (pp. 523-529). Montevideo: FCU.

Olivera García, R. M. (2009). Cuatro bases fundamentales de la nueva Ley de Concursos y Reorganización Empresarial. Revista de la Facultad de Derecho, (29), 207-216. 
Olivera García, R. M. (2008). Principios y bases de la nueva Ley de Concursos y Reorganización Empresarial. Montevideo: FCU.

Prendes Carril, P. (2009).Presupuesto objetivo. En Prendes Carril (Dir.), Tratado práctico concursal, t. 1. Cizur Menor-Navarra: Aranzazi.

Rodríguez Mascardi, T. et alt. (2011). Cuadernos de Derecho Concursal (2ª ed.). Montevideo: FCU.

Rodríguez Olivera, N. E. (2005). Manual de Derecho Comercial Uruguayo, v. 6, t. 1. Montevideo: FCU.

Rojo Fernández-Río, Á. (2008). Presupuesto objetivo. En Rojo y Beltrán (Dirs.), Comentario de la Ley concursal, t. I, (pp. 164-193). Madrid: Civitas.

Ruy de Alburquerque, P. (2007). A declaração da situação de insolvência. En Ruy de Alburquerque y Menezes Cordeiro (Coords.), Estudos em Memória do Professor Doutor José Dias Marques, (pp. 773-793). Coimbra: Almedina.

Serra, C. (2018). Lições de Direito da Insolvência. Coimbra: Almedina.

Serra, C. (2012). O Regime Português da Insolvência (5a ed.). Coimbra: Almedina.

Suárez-Llanos Gómez, L. (2005). El presupuesto objetivo del concurso: el estado de insolvencia. En Quintana Carlo, Bonet Navarro y García-Cruces González (Dirs.), Las claves de la Ley concursal, (pp. 35-48). Cizur Menor-Navarra, Aranzadi.

Tarigo, E. (2004). Lecciones de Derecho Procesal Civil, t. II. Montevideo: FCU.

\section{Notas}

1 «Síntomas de endeudamiento en exceso», visitado el 11 de setiembre en https://www.bcu.gub.uy/Usuario-Financiero/Paginas/Presupuesto-Exceso.aspx

${ }^{2}$ Xavier de Mello, E., «La composición de la crisis del sobreendeudamiento en Uruguay», https://servizi.dobank.com/attach/Content/Eventi/3615/o/demello.pdf, descargado el 1 de octubre de 2018, pp. 1-3 
${ }^{3}$ Fernández C., Portugal Duarte, A. y Simões, M., «A dinámica do endividamento das famílias portuguesas após a adesão de Portugal à União Europeia», Boletim de Ciências Económicas. Homenagem ao Prof. Doutor António José Avelãs Nunes, v. LVII, pp. 1433-1462 (Coimbra: Facultade de Direito, 2014), pp. 1433,1435, 1436 y 1458.

${ }^{4}$ Gonçalves Ferreira, J., A exoneração do passivo restante (Coimbra: Coimbra Editora, 2013), pp. 13 y 14; Cordeiro Santos, A., «O endividamento das famílias portuguesas: um fenómeno sistémico», in: Cordeiro Santos (coord.), Famílias Endividadas. Uma abordagem de economía política e comportamental, pp. 17-42, (Coimbra: Almedina, 2015), pp. 22, 34 y 35.

${ }^{5}$ Direção-Geral da Política de Justiça, «Estatísticas trimestrais sobre processos de insolvência, processos especiais de revitalização e processos especiais para acordo de pagamento (2007-2018)», Boletim de Informação Estatística Trimestral, n. 60 (Direção-Geral da Política de Justiça, 2019).

${ }^{6}$ Frade, C. C., Ferreira, «O perdão de dívidas na insolvencia das famílias», in: Cordeiro Santos (coord.), Famílias Endividadas. Uma abordagem de economía política e comportamental, pp. 133-146, (Coimbra: Almedina, 2015), p. 134.

${ }^{7}$ Rojo Fernández-Río, Á., «Problemas y cuestiones en torno al sobreendeudamiento e insolvencia de las familias españolas», en: Tomillo Urbina y Álvarez Rubio (Dirs.), El futuro de la protección jurídica de los consumidores. Actas del I Congreso Euroamericano de Protección Jurídica de los Consumidores, pp. 251-254 (Cizur Menor-Navarra: Civitas, 2008), pp. 253 y 254.

${ }^{8}$ Según la Encuesta de Condiciones de Vida (ECV) realizada con criterios armonizados para todos los países de la Unión Europea.

${ }^{9}$ García Chamorro intenta varias explicaciones: la complejidad del procedimiento que parece encajar en la persona jurídica y no en la natural, la falta de difusión, la adopción tardía de la medida (García Chamorro, O., «Aproximación estadística al régimen de la Segunda Oportunidad», en: Pardo Ibánez (coord.), El mecanismo de la segunda oportunidad. Del acuerdo extrajudicial de pagos al beneficio del pasivo insatisfecho, pp. 24-32 (Madrid: Bosch, 2017), pp. 25, 27 y 31).

${ }^{10}$ La información aquí proporcionada fue extraída del portal estadístico que lleva y 
mantiene al día el Poder Judicial de España y que se puede consultar en www. poderjudicial.es

${ }^{11}$ Voz «inminente», Diccionario de la Real Academia Española.

12 Cuestión advertida por Germán Florio, quien concluye que al deudor la Ley uruguaya no le exige probar que no puede cumplir con sus obligaciones, sólo le exige agregar la documentación referida en el artículo 7 (Germán Florio, C.D., Concurso y estado de insolvencia (Montevideo: La Ley, 2017), pp. 54 y 60).

${ }^{13}$ Bado Cardozo, V.S., y López Rodríguez, C.E., «Presupuestos del concurso», en: López Rodríguez (Dir.), pp. 55-98 (Montevideo: La Ley, 2012), p. 65.

${ }^{14}$ Se sigue a la PALC al pie de la letra puesto que en la norma española proyectada el artículo 5 establecía que: La solicitud de declaración judicial de concurso instada por el deudor se considerará por si sola reconocimiento de estado de insolvencia.

${ }^{15}$ Holz Brandus, E.R. y Rippe Káiser, S., Reorganización empresarial y concursos. Ley 18.387 (Montevideo: FCU, 2009), p. 95; Rodríguez Mascardi, T. et alt., Cuadernos de Derecho Concursal, 2a ${ }^{\mathrm{a}}$. ed. (Montevideo: FCU, 2011), p. 60; Germán Florio, Concurso..., p. 65.

${ }^{16}$ Solución que, por otra parte, ha sido objeto de observación. Germán Florio advierte que, ante la confesión del deudor, no se le permite al juez ingresar a cuestionar si se ha configurado o no el estado de insolvencia y que son tan gravosas las consecuencias que apareja el concurso para la persona del deudor que la norma apenas ha reparado en la eventualidad de solicitudes frívolas o hasta fraudulentas (Germán Florio, C.D., «Concepto de insolvencia en el concurso», en: Miller, Ferrer y Ayul (Dirs.), «Estudios de Derecho Concursal. Diez años de la Ley de Concursos y Reorganización Empresarial, pp. 387-418 (Montevideo: La Ley, 2018, p. 413).

17 Olivera García, R.M., Principios y bases de la nueva Ley de Concursos y Reorganización Empresarial (Montevideo: FCU, 2008), pp. 26 y 27. Sobre el punto Creimer Bajuk ha planteado que la detección prematura de las crisis empresariales puede tener el inconveniente de la mala reputación que supone al deudor (Creimer Bajuk, I., «El presupuesto objetivo del concurso», en: Crisis y Derecho. Las vías de prevención y saneamiento de la crisis empresarias, pp. 53-61 (Córdoba: Fundación para el Estudio de la Empresa, 2015), p. 59). 
${ }^{18}$ Olivera García, R.M., «La insolvencia empresarial y la eficacia de la herramienta concursal», en: Miller, Ferrer y Ayul (Dirs.), Estudios de Derecho Concursal. Diez años de la Ley de Concursos y Reorganización Empresarial, pp. 31-72 (Montevideo: La Ley, 2018), pp. 44-48 y, asimismo en: «Cuatro bases fundamentales de la nueva Ley de Concursos y Reorganización Empresarial», Revista de la Facultad de Derecho, n. 29, pp. 207-216 (Montevideo: Facultad de Derecho-Universidad de la República, 2009), p. 210; «La insolvencia como presupuesto del concurso», en: Olivera García (Dir.), Panorama de Derecho Concursal, pp. 39-44 (Montevideo: FCU, 2018), p. 42 y en «La insolvencia como presupuesto del concurso», en: AA.VV., Tres Pilares del Moderno Derecho Comercial, pp. 523-529 (Montevideo: FCU, 2011), p. 526. Asimismo, en coautoría con Chalar Sanz, en: Olivera García (Dir.), Panorama de Derecho Concursal, pp. 13-27 (Montevideo: FCU, 2018), p. 17. Son de la misma opinión Germán Florio, «Concepto de ...», op. cit., p. 393 y Martínez Blanco, C., Manual de Derecho Concursal. De los orígenes de las crisis empresariales a la Ley $N^{\circ} 18.387$ y su aplicación, $3^{\text {a }}$ ed. (Montevideo: FCU, 2018), p. 162.

${ }^{19}$ También pueden acceder a este fondo cuando acrediten encontrarse en estado de insolvencia.

${ }^{20}$ Serra realiza un detalle de todas las normas en las que se utiliza este concepto en Lições..., p. 310, nota 460.

${ }^{21}$ A los efectos del CIRE, la empresa es toda organización de capital y trabajo destinada al ejercicio de cualquier actividad económica (art. 5). 